\title{
Solution combustion synthesis using Schiff-base aluminum complex without fuel and optical property investigations of alumina nanoparticles
}

\author{
Mehdi Salehi $^{1} \cdot$ Ehsan Arabsarhangi $^{1}$
}

Received: 12 December 2014/Accepted: 13 April 2015/Published online: 1 May 2015

(C) The Author(s) 2015. This article is published with open access at Springerlink.com

\begin{abstract}
Synthesis of alumina nanomaterials via a solution combustion technique using Schiff base aluminum (III) complex at 820 and $950{ }^{\circ} \mathrm{C}$ for $4 \mathrm{~h}$ was performed successfully. The synthesis procedure was performed using the complex in the absence and presence of urea and glycine as fuel for comparison. The obtained data showed that the procedure without using fuel resulted in a better phase and morphology. To investigate the phase formation, powder $\mathrm{X}$-ray diffraction technique was used. Also, SEM micrographs were used to investigate the morphology of the obtained materials. The optical properties of the obtained materials were studied by FTIR spectra. According to the PXRD data, it was found that with annealing at $950{ }^{\circ} \mathrm{C}$, the phase formation of the obtained materials showed cubic crystal structure with cell parameter $a=3.14 \AA$ for gamma phase. Also, by annealing at $820{ }^{\circ} \mathrm{C}$ using fuels for $4 \mathrm{~h}$, the main phase was found to be in gamma.
\end{abstract}

Keywords Alumina - Solution combustion - Schiff base · Nanomaterial

\section{Introduction}

Aluminum oxide $\left(\mathrm{Al}_{2} \mathrm{O}_{3}\right)$ is one of the most important industrial materials, which is widely used as adsorbent [1], catalyst [2], catalyst support [3, 4], functional ceramics [5, 6], reinforcement for composite material abrasives [7], ceramic materials, imitation jewelry [8,9], sorbents and catalysts [10], dosimeters [11], and so on because of its low-cost,

Mehdi Salehi

msalehi@semnan.ac.ir

1 Department of Chemistry, Semnan University, Semnan, Iran good thermal stability, and high-specific surface area [12, 13]. Moreover, it is a major ingredient for the preparation of complex oxides because of its promising luminescent [14], thermoluminescent [15], and scintillation properties [16].

Several procedures have reported the synthesis of different alumina nanomaterial phases such as precipitation [17], spray pyrolysis [18], sol-gel reactions [19], methods utilizing different surfactants as a template [20], formation of solid precursors of aluminum hydroxides or oxyhydroxides with various compositions, and crystallinity [21]. The aim of this article is to investigate the preparation of nano-alumina by a novel solution combustion method using a complex and without using fuel. To compare the synthesis procedure with the condition in the present fuel, different fuels were used at a temperature of $820{ }^{\circ} \mathrm{C}$. So, to the best of our knowledge, the investigation of synthesis of $\mathrm{Al}_{2} \mathrm{O}_{3}$ from this method and using the raw materials has not been reported.

\section{Materials and methods}

Synthesis of the ligand $N, N^{\prime}-$

Bis(salicylidene)ethylenediamine (salen)

Certain amounts of ethylenediamine (en) and salicylaldehyde were mixed together in a 1:2 molar ratio. The obtained precipitate was dissolved in a hot ethanol and then filtered.

\section{Synthesis of complex $\left[\mathrm{Al}(\mathrm{salen})_{3}\left(\mathrm{H}_{2} \mathrm{O}\right)_{2}\right] \mathrm{NO}_{3}$}

Certain amounts of aluminum nitrate and the synthesized ligand in a 1:2 molar ratio were used. First, the aluminum nitrate and the ligand were dissolved in a hot ethanol 
separately, and the aluminum solution was added to the ligand solution slowly. The obtained material resembles a white precipitate. The obtained material was filtered and washed with ethanol. Yield: $65 \%$. Analysis calculated for $\mathrm{C}_{16} \mathrm{H}_{18} \mathrm{AlN}_{3} \mathrm{O}_{7}(\%): \mathrm{C}, 49.11 ; \mathrm{H}, 4.64 ; \mathrm{N}, 10.74$. Found (\%): C, 48.55; H, 4.57; N, 10.65 .

\section{Synthesis of nano-alumina}

To obtain a clear solution, a certain amount of the synthesized complex was dissolved in distilled water. Also, two solutions using the two different fuels were prepared. The solution was heated at $60{ }^{\circ} \mathrm{C}$ to obtain a gel. Then, the gel was annealed at $450{ }^{\circ} \mathrm{C}$ for $4 \mathrm{~h}$. The obtained materials were in black-like form. To eliminate the residual organic components, the powders were heated more at 820 or $950{ }^{\circ} \mathrm{C}$ for $4 \mathrm{~h}$.

\section{Results and discussion}

\section{Powder X-ray diffraction (PXRD) analysis}

Phase characterization of the obtained materials was investigated using PXRD technique with $\mathrm{CuK} \alpha$ radiation at the range of $10^{\circ}-90^{\circ}$ and the step of $0.05^{\circ}$. Figures 1,2 and 3 show the X-ray diffraction (XRD) patterns of the obtained alumina nanomaterials. Figure 1 shows the XRD pattern of the obtained material without using any fuel to synthesize alumina annealed at $950{ }^{\circ} \mathrm{C}$ for $4 \mathrm{~h}$. As shown in Fig. 1, the main phase for the synthesized material is beta (JCPDScard number: 100414) and gamma (JCPDS card number: 011307) nano-alumina. Also, Fig. 2 shows the PXRD pattern of the obtained material using urea as fuel for the synthesis of nano-alumina at $820^{\circ} \mathrm{C}$ for $4 \mathrm{~h}$. The figure shows that the main phase is actually gamma

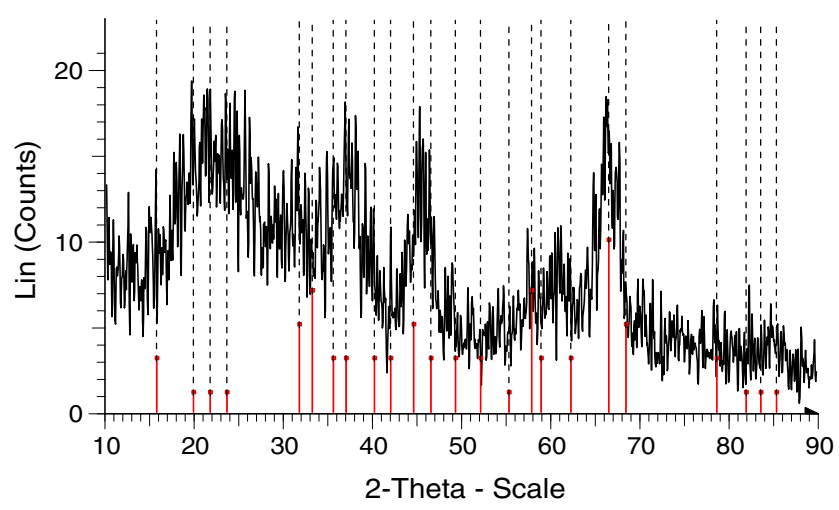

Fig. 1 PXRD pattern of the synthesized a multi-phase beta and gamma nano-alumina via a solution combustion method without using fuel at $950{ }^{\circ} \mathrm{C}$ for $4 \mathrm{~h}$

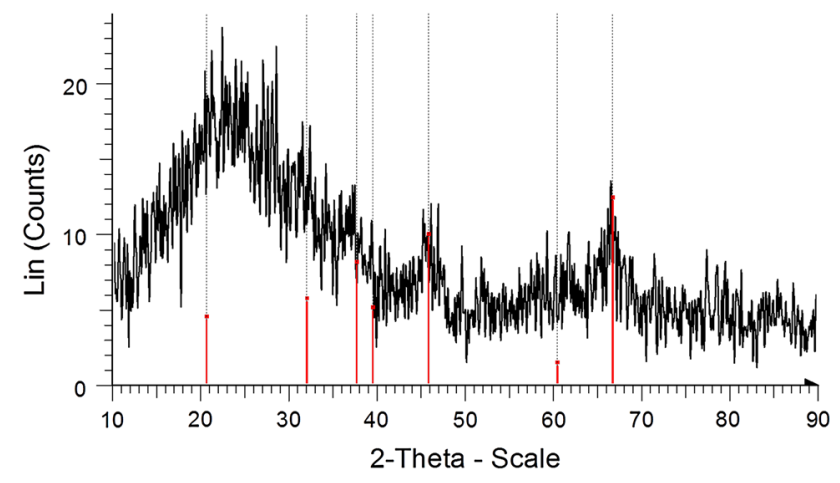

Fig. 2 PXRD pattern of the synthesized gamma nano-alumina via a solution combustion method using urea as fuel at $820{ }^{\circ} \mathrm{C}$ for $4 \mathrm{~h}$

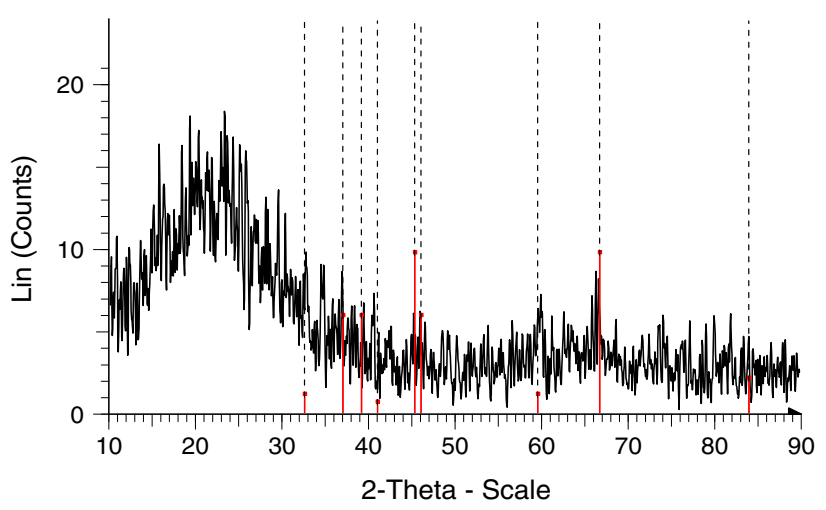

Fig. 3 PXRD pattern of the synthesized gamma nano-alumina via a solution combustion method using glycine as fuel at $820^{\circ} \mathrm{C}$ for $4 \mathrm{~h}$

(JCPDS card number: 040858) nano-alumina. Moreover, Fig. 3 shows the PXRD pattern of the obtained material using glycine as fuel to synthesize alumina at $820{ }^{\circ} \mathrm{C}$ for $4 \mathrm{~h}$. The figure shows that the main phase is gamma (JCPDS card number: 291486) nano-alumina. As shown in Figs. 1, 2 and 3, it is clear that with using fuel for the synthesis of nano-alumina, the obtained phase is nearly pure gamma alumina. However, when the reaction was performed without using any fuel, the obtained phase was a mixture of beta and gamma nano-alumina. But the ratio of gamma to beta phase was 0.89 . It shows that the ratio of gamma phase in the synthesized nanomaterial is about $45 \%$.

\section{Morphology analysis}

Figure 4 shows the scanning electron microscopic (SEM) images of the synthesized nanomaterials via a combustion method without using fuel, annealed at $950{ }^{\circ} \mathrm{C}$ for $4 \mathrm{~h}$. Figure 4 a shows the low-magnification image of the synthesized material. It is clear that the sample is in a porouslike structure. It shows that the porosity distribution is nearly homogeneous. Figure $4 \mathrm{~b}$ shows that the porosity is 
Fig. 4 SEM images of the obtained materials from the combustion method without using fuel annealed at $950{ }^{\circ} \mathrm{C}$ for $4 \mathrm{~h}$

Fig. 5 SEM images of the obtained materials from the combustion method without using fuel annealed at $820{ }^{\circ} \mathrm{C}$ for $4 \mathrm{~h}$
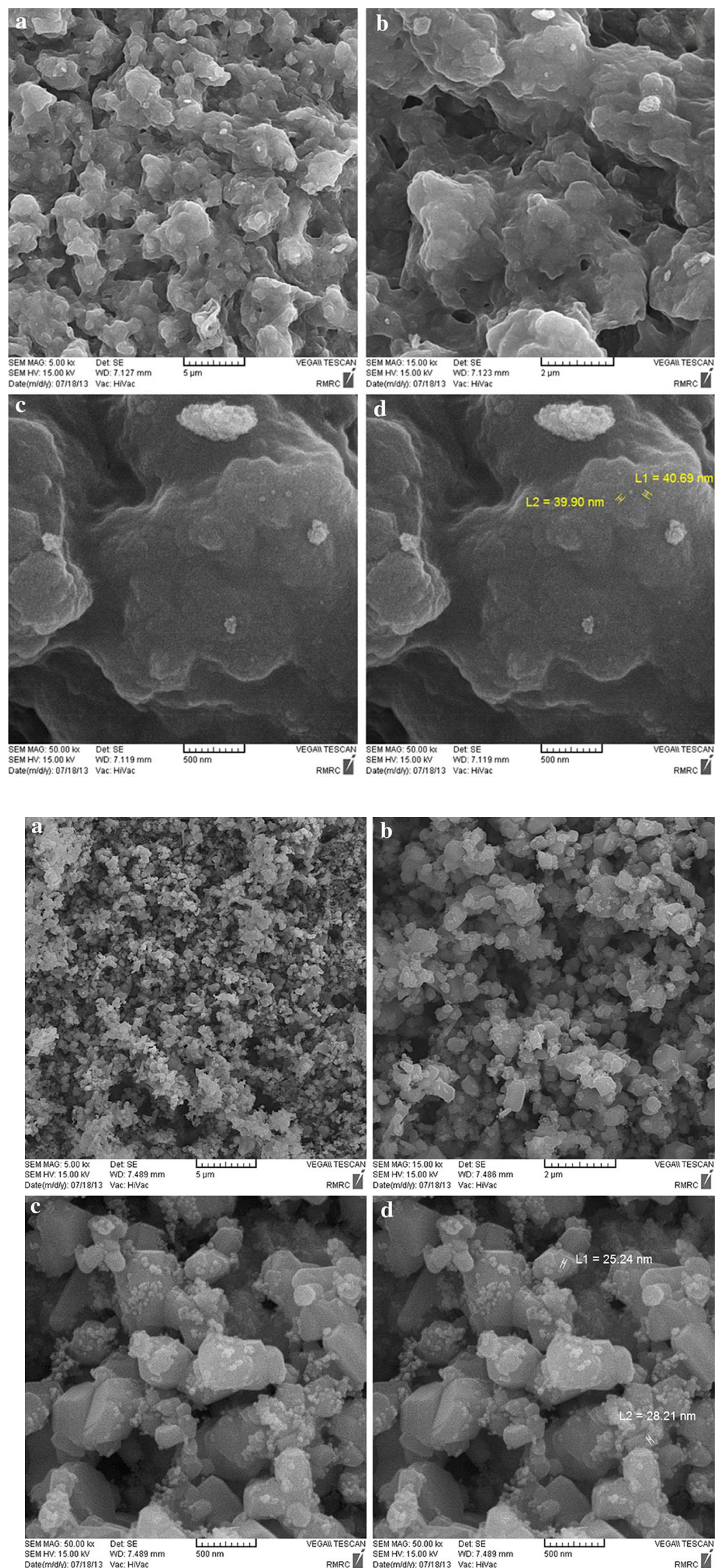
Fig. 6 SEM images of the obtained materials from the combustion method using urea as fuel annealed at $820^{\circ} \mathrm{C}$ for $4 \mathrm{~h}$
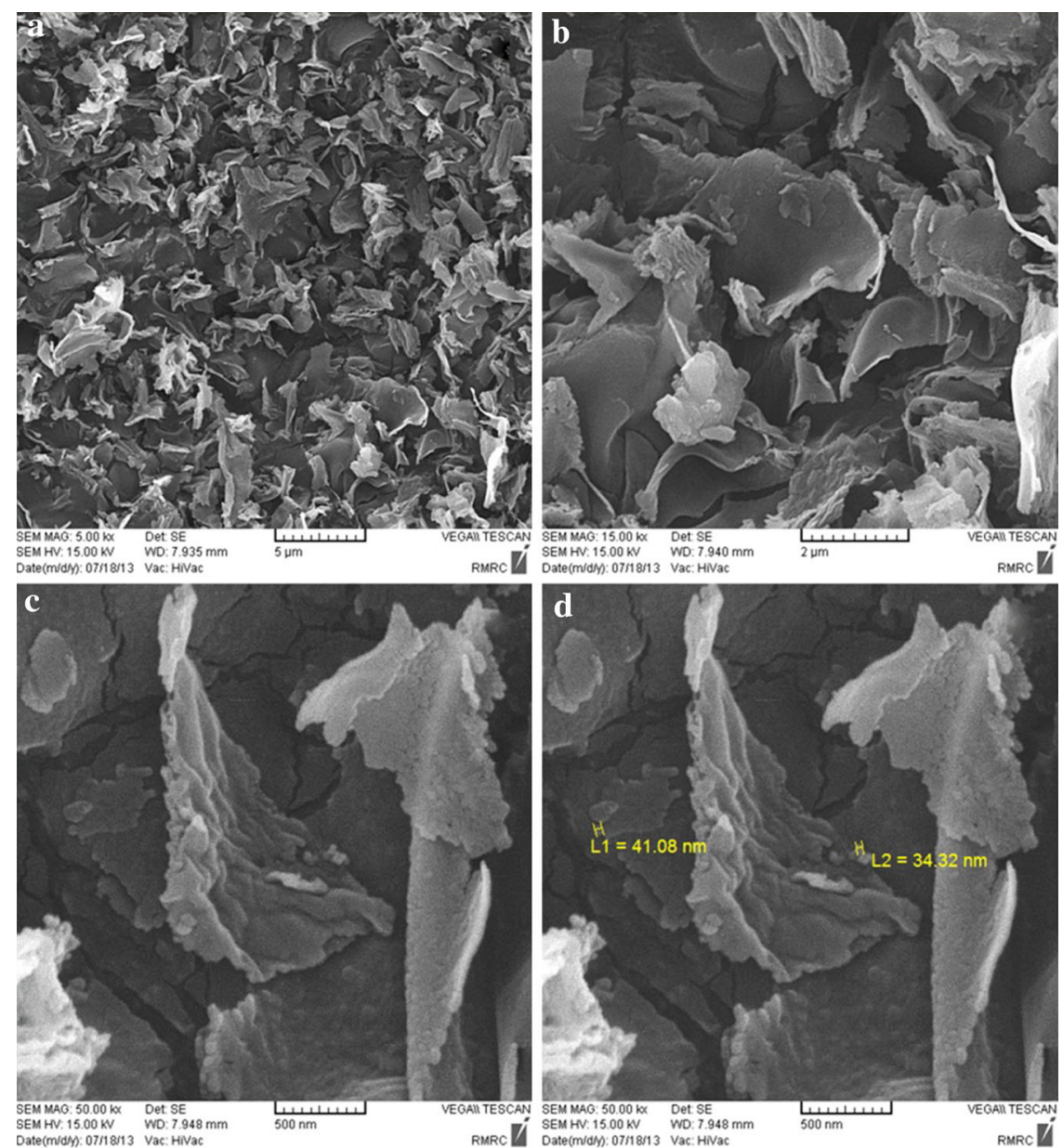

in micro-porosity range. It shows that the porosity diameter is in a range of about 50-200 $\mathrm{nm}$. Figure $4 \mathrm{c}$ and $\mathrm{d}$ shows the high-magnification image of the synthesized nanomaterials. It is clear that there are small particles, as uncus, on the synthesized materials. It shows that the particle sizes are in a range of about $40-200 \mathrm{~nm}$ in diameter.

Figure 5 shows the SEM images of the synthesized nanomaterials via a combustion method without using fuel, annealed at $820^{\circ} \mathrm{C}$ for $4 \mathrm{~h}$. Figure 5a shows the lowmagnification image of the synthesized material. It is clear that the sample is in a grain-like structure. It shows that the size and morphology distribution is nearly homogeneous. Figure $5 \mathrm{~b}$ shows that there is porous structure in the analyzed sample. Figure 5c shows that the porosity size is in micro-porosity range. It also shows that the porosity diameter is in a range of about 100-150 nm. Figure 5d shows the high-magnification image of the synthesized nanomaterials. It is clear that the large particle's diameter is in the range of about $200-500 \mathrm{~nm}$, and the small particles, as uncus on the synthesized materials, are in a range of about $25-50 \mathrm{~nm}$ in diameter.

Figure 6 shows the SEM images of the synthesized nanomaterials via a combustion method using urea as fuel, annealed at $820{ }^{\circ} \mathrm{C}$ for $4 \mathrm{~h}$. Figure $6 \mathrm{a}$ and b shows the lowmagnification image of the synthesized material. It is clear that the sample is in a flake-like structure. It shows that the size and morphology distribution is nearly homogeneous. Figure $6 \mathrm{c}$ shows that the size of the thickness of the flakes is about $50-80 \mathrm{~nm}$. Figure $6 \mathrm{~d}$ shows the high-magnification image of the synthesized nanomaterials. It is clear that the length of the flakes is in the range of about $2-3 \mu \mathrm{m}$.

Figure 7 shows the SEM images of the synthesized materials via a combustion method using glycine as fuel, annealed at $820^{\circ} \mathrm{C}$ for $4 \mathrm{~h}$. Figure $7 \mathrm{a}$ and b shows the lowmagnification image of the synthesized material. It is clear that the sample is a porous-like structure with small particles on the sample. It shows that the size and morphology distribution is nearly homogeneous. Figure $7 \mathrm{c}$ and d shows the high-magnification image of the synthesized material. It is clear that the size of the diameter of the pores is in the range of about $70-100 \mathrm{~nm}$, and the particle sizes are in a range of about $30-50 \mathrm{~nm}$.

Figure $8 \mathrm{a}-\mathrm{b}$ shows the Fourier transform infrared (FTIR) spectra of the synthesized nanomaterials via a combustion method at different conditions. The FTIR spectrum of the synthesized nanomaterial annealed at 
Fig. 7 SEM images of the obtained materials from the combustion method using glycine as fuel annealed at $820{ }^{\circ} \mathrm{C}$ for $4 \mathrm{~h}$

Fig. 8 FTIR spectrum of the synthesized nanomaterial via a combustion method without using any fuel at $a 820^{\circ} \mathrm{C}$, $b 850{ }^{\circ} \mathrm{C}, c$ using urea as fuel at $820{ }^{\circ} \mathrm{C}$ and $d$ using glycine as fuel at $820{ }^{\circ} \mathrm{C}$ for $4 \mathrm{~h}$
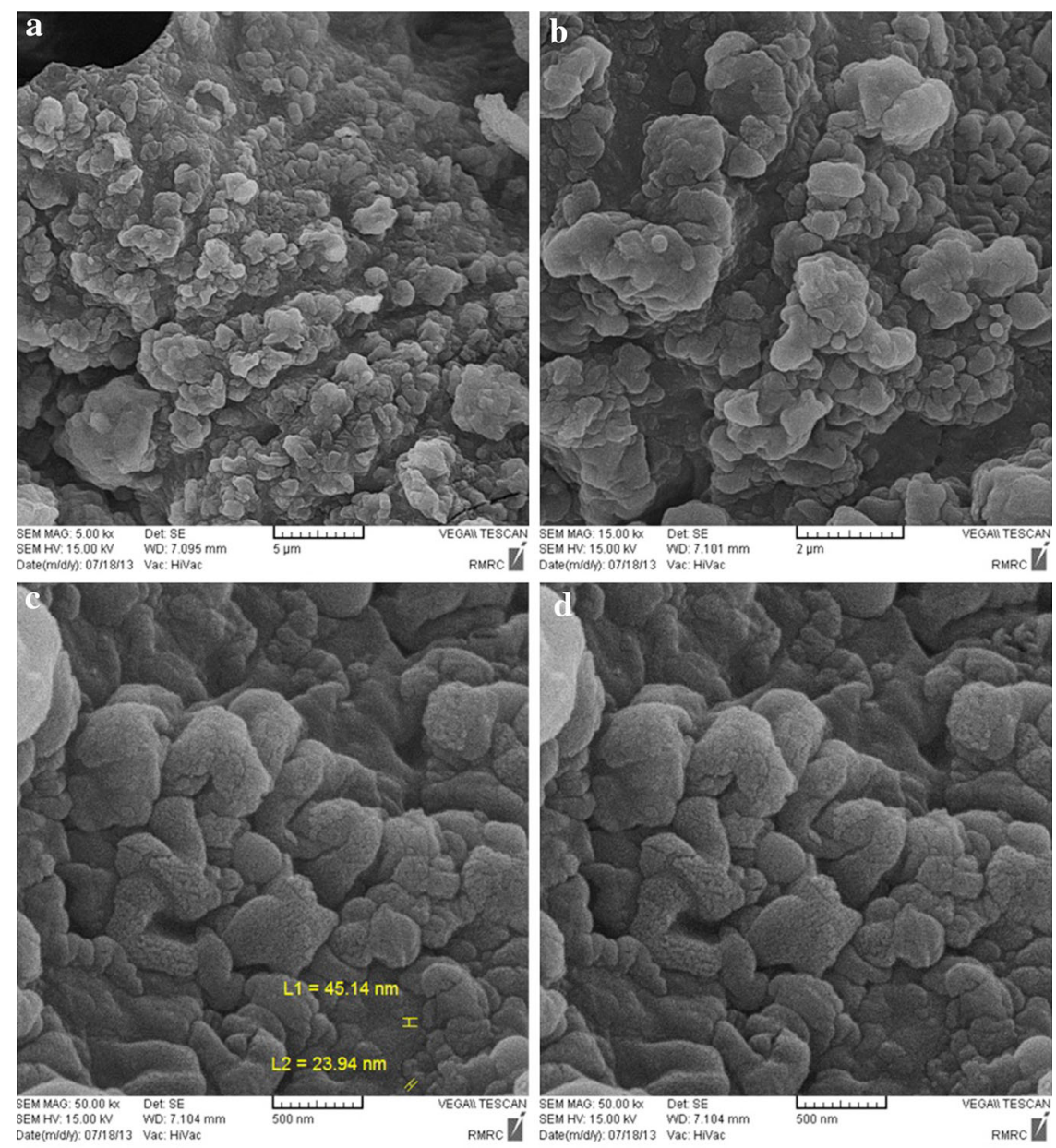

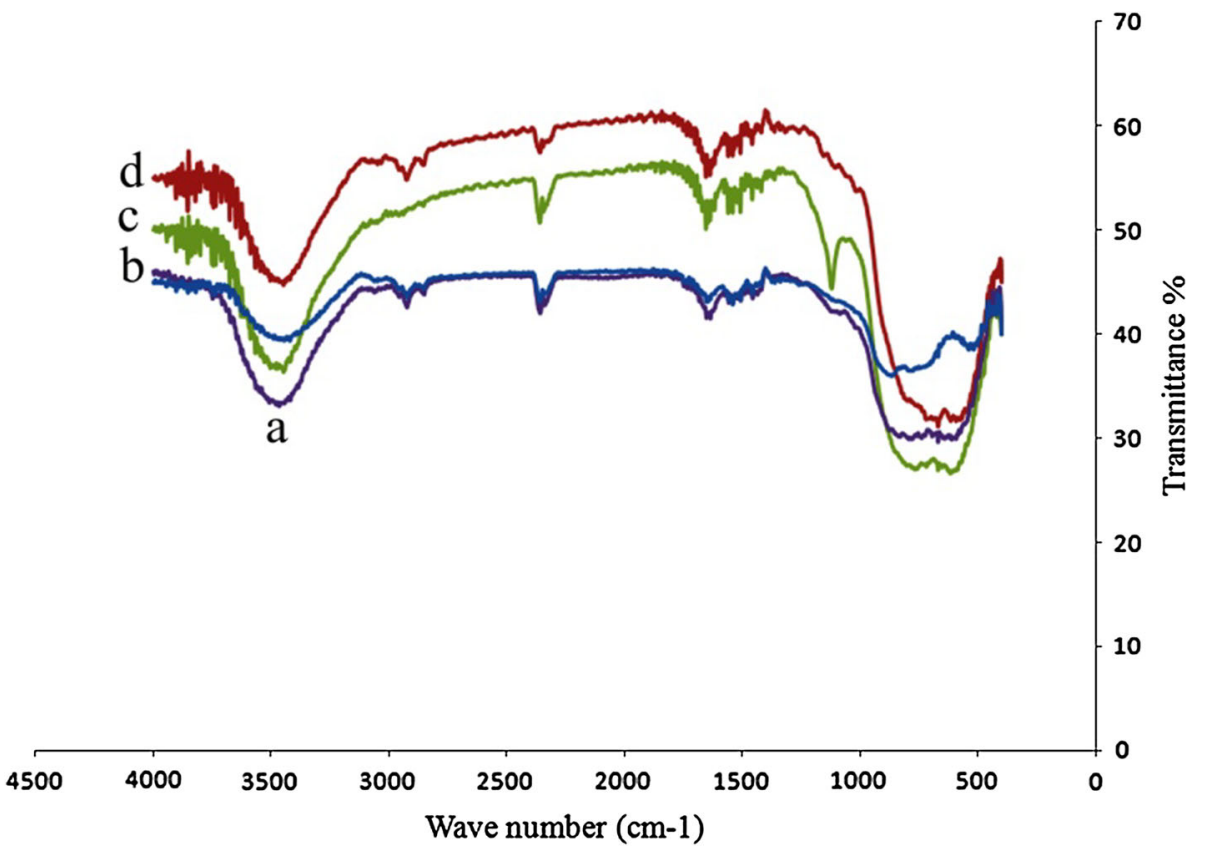


$950{ }^{\circ} \mathrm{C}$ is shown in Fig. 8. The peaks at $1625-1650 \mathrm{~cm}^{-1}$ are assigned to the bending vibrations of the hydroxide. The weak peaks at 1508 and $2340 \mathrm{~cm}^{-1}$ are assigned to nitrate and carbonate. Figure $8 \mathrm{~b}$ shows the FTIR spectrum of the synthesized nanomaterial annealed at $820{ }^{\circ} \mathrm{C}$ for $4 \mathrm{~h}$. The peaks at 400 to $900 \mathrm{~cm}^{-1}$ are assigned to Al-O vibrations [22]. The peaks at $500-570 \mathrm{~cm}^{-1}$ are assigned to $\mathrm{AlO}_{6}$, and the peaks at $675-775 \mathrm{~cm}^{-1}$ are assigned to $\mathrm{AlO}_{4}$. Also, the peaks at $1635 \mathrm{~cm}^{-1}$ are assigned to the bending vibrations of hydroxide vibrational mode, and the peak around $3480 \mathrm{~cm}^{-1}$ is assigned to the stretching vibration of hydroxide.

\section{Conclusion}

Synthesis of nano-alumina with different conditions was performed successfully. PXRD data showed that the main phase for all of the synthesized nanomaterials was gamma. It showed that the nanomaterials were synthesized with high purity. SEM images showed that the synthesized nanomaterials were in different morphology depending on the synthesis procedure. It is clear that reaction temperature is a main factor on the synthesized nanomaterial's morphologies. However, it showed that the fuel type is also an important factor on the morphology of the synthesized nanomaterials. The SEM images showed that the morphology of the obtained materials is in the form of porous particle and irregular particle shape. FTIR spectra of the nano-alumina were investigated in different synthesis conditions.

Acknowledgments We thank Semnan University for supporting this study.

Open Access This article is distributed under the terms of the Creative Commons Attribution 4.0 International License (http:// creativecommons.org/licenses/by/4.0/), which permits unrestricted use, distribution, and reproduction in any medium, provided you give appropriate credit to the original author(s) and the source, provide a link to the Creative Commons license, and indicate if changes were made.

\section{References}

1. Mahmoud, M.E., Osman, M.M., Hafez, O.F., Elmelegy, E.J.: Adsorption equilibrium and kinetics of fluoride on sol-gelderived activated alumina adsorbents. Colloid Interface Sci. 349, 307-313 (2010)

2. Gong, S.F., Shinozaki, A., Shi, M.L., Qian, E.W.: Hydrotreating of jatropha oil over alumina based catalysts. Energy Fuels 26, 2394-2399 (2012)

3. Gaudet, J.R., Riva, A., Peterson, E.J., Bolin, T., Datye, A.K.: Improved low-temperature $\mathrm{CO}$ oxidation performance of $\mathrm{Pd}$ supported on La-stabilized alumina. Am. Chem. Soc. Catal. 3, 846-855 (2013)
4. Puron, H., Pinilla, J.L., Berrueco, C., Fuente, J.A., Millan, M.: Hydrocracking of maya vacuum residue with NiMo catalysts supported on mesoporous alumina and silica-alumina. Energy Fuels 27, 3952-3960 (2013)

5. Zhou, X., He, X., Su, B.: Ultrasonic synthesis of the microporous metal-organic framework $\mathrm{Cu}_{3}(\mathrm{BTC})_{2}$ at ambient temperature and pressure: An efficient and environmentally friendly method. Mater. Lett. 63, 830-832 (2009)

6. Qi, Y.E., Zhang, Y.S., Fang, Y., Hu, L.T.: Design and preparation of high-performance alumina functional graded self-lubricated ceramic composites. Compos Part B Eng. 47, 145-149 (2013)

7. Zhu, Z.F., Liu, H., Sun, H.J., Yang, D.: PEG-directed hydrothermal synthesis of multilayered alumina microfibers with mesoporous structures. Microporous Mesoporous Mater. 123, 39-44 (2009)

8. Furukawa, M.: Alumina ceramic tools. Am. Ceram. Soc. Bull. 62, 1384-1387 (1983)

9. Uhlmann, D.R., Teowee, G.: Sol-gel science and technology: current state and future prospects. J. Sol-Gel. Sci. Technol. 13, 153-162 (1998)

10. Cejka, J., Kooyman, P.J., Vesela, L., Rathousky, J., Zukal, A.: High-temperature transformations of organised mesoporous alumina. Phys. Chem. Chem. Phys. 4, 4823-4829 (2002)

11. Cejka, J.: Organized mesoporous alumina: synthesis, structure and potential in catalysis. Appl. Catal. A 254, 327-338 (2003)

12. Das, K., Ray, S.S., Chapple, S., Wesley-Smith, J.: Mechanical, thermal, and fire properties of biodegradable polylactide/boehmite alumina composite. Ind. Eng. Chem. Res. 52, 6083-6091 (2013)

13. Renuka, N.K., Shijina, A.V., Praveen, A.K.: Mesoporous $\gamma$-alumina nanoparticles: synthesis, characterization and dye removal efficiency. Mater. Lett. 82, 42-44 (2012)

14. Muthe, K.P., Kulkarni, M.S., Rawat, N.S., Mishra, D.R., Bhatt, B.C., Singh, A., Gupta, S.K.: Melt processing of alumina in graphite ambient for dosimetric applications. J. Lumin. 128, 445-450 (2008)

15. Peng, C.H., Hwang, C.C., Hsiao, C.S.: Judd-Ofelt analysis and optically stimulated two-photon absorption of Yb3+-doped $\mathrm{NdAl}_{3}\left(\mathrm{BO}_{3}\right)_{4}$ single crystals. J. Alloys Compd. 491, 29-32 (2010)

16. Henaish, B.A., El-Agrami, A.M., Abdel-Fattah, W.I., Osiris, W.G.: Characteristic thermoluminescence of gamma-irradiated alumina ceramics doped with some alkali metals. Radiat. Phys. Chem. 44, 73-77 (1994)

17. Ogino, H., Yoshikawa, A., Nikl, M., Krasnikov, A., Kamada, K., Fukuda, T.: Growth and scintillation properties of Pr-doped $\mathrm{Lu}_{3} \mathrm{Al}_{5} \mathrm{O}_{12}$ crystals. J. Cryst. Growth 287, 335-338 (2006)

18. Kim, J.H., Jung, K.Y., Park, K.Y., Cho, S.B.: Characterization of mesoporous alumina particles prepared by spray pyrolysis of $\mathrm{Al}\left(\mathrm{NO}_{3}\right)_{2} \quad 9 \mathrm{H}_{2} \mathrm{O}$ precursor: effect of CTAB and urea. MicroporousMesoporous Mater. 128, 85-90 (2010)

19. Jayaraman, V., Gnanasekaran, T., Periaswami, G.: Low-temperature synthesis of $\beta$-aluminas by a sol-gel technique. Mater. Lett. 30, 157-162 (1997)

20. Aguado, J., Escola, J.M., Castro, M.C.: Influence of the thermal treatment upon the textural properties of sol-gel mesoporous $\gamma$ alumina synthesized with cationic surfactants. MicroporousMesoporous Mater. 128, 48-55 (2010)

21. Zhang, X., Honkanen, M., Levänen, E., Mäntyla, T.: Transition alumina nanoparticles and nanorods from boehmite nanoflakes. J. Cryst. Growth. 310, 3674-3679 (2008)

22. Nemade, K.R., Waghuley, S.A.: Low temperature synthesis of semiconducting $\alpha-\mathrm{Al}_{2} \mathrm{O}_{3}$ quantum dots. Ceram. Int. 40, 6109-6113 (2014) 